\title{
Study on the Application of Recycled Fine Powder in Ready-Mixed Concrete
}

\author{
Lan Cong , Lu Jialin, Chen Jing, Wu Hailun, and Liu Dong \\ China West Construction Group Southwest Co., LTD, Chengdu, 610052, China
}

\begin{abstract}
The basic properties of the fly ash, recycled brick powder and recycled concrete powder, compared the recycled brick powder and recycled concrete powder instead of fly ash in concrete preparation, influence on the working performance and mechanical properties; and through the modifier to improve the concrete slump loss is too large, analyzes the mechanism of change influence of modifiers on mechanical properties of concrete. The results showed that the recycled brick powder and recycled concrete powder in certain fineness conditions, its performance with fly ash; retarder, activator and some surfactant composition modifier has obvious effect on the working performance and mechanical properties; and hydration calcium silicate aluminum increased the role of large the mechanical properties of concrete.
\end{abstract}

\section{Foreword}

With the rapid urbanization process in China and the continuous increase in the production of construction waste, the ecological environmental problems should be unavoidable. During the 13th five-year period, the State put the utilization of construction waste resources into an important position.. At present, the waste resource is mainly used to prepare inorganic mixture, regenerated brick, regenerated block, and a small number of regenerated mortar and regenerated concrete. At present, the research on this kind of waste resource is more systematic and occupies the dominant position of regenerated waste [1]. The Portland cement accounts for about $5 \%$ of greenhouse gas emissions incurred globally [2], and Reasonable reduction of carbon dioxide emissions and mitigation of greenhouse effect are also issues that need to be solved in the concrete industry. In terms of policy, resource acquisition and production cost, the cost of recycled aggregate is not competitive with that of natural materials. Many researchers have begun to explore the development and manufacture of recycled powder with high added value 。 Regenerated micropowder is a kind of fine powder which is divided into waste concrete and waste clay brick by stages, broken step by step and ground to a certain fineness. The glass phase and amorphous material, such as unhydrated cement particles in waste concrete and clay sintered in waste clay brick, can be used as mineral admixture of concrete and mortar to give full play to its filling and effect [1,3 5]。 At present, many researches have been carried out on the mechanical properties and durability of the regenerated micro-powder, but the reasons such as the porous and rough surface of the regenerated micropowder have caused the high water consumption and the high loss of working property, which limits its large-scale application in commercial concrete [6-12]r.

\section{Materials and methods}

\subsection{Materials}

Cement: The ordinary Portland cement of $42.5 \mathrm{R}$ grade conforming GB175, the specific performance indicators are shown in Table 1.

Fly ash: II fly ash, fineness $(45 \mu \mathrm{m}$ square hole sieve

Table 1. the basic performance indicators of cement

\begin{tabular}{|c|c|c|c|c|c|c|c|c|}
\hline \multirow{2}{*}{$\begin{array}{c}\text { Standard } \\
\text { consistency } / \%\end{array}$} & \multirow[b]{2}{*}{ Fineness/\% } & \multirow[b]{2}{*}{ Stability } & \multicolumn{2}{|c|}{ Setting time $/ \mathrm{min}$} & \multicolumn{2}{|c|}{$3 \mathrm{~d} / \mathrm{MPa}$} & \multicolumn{2}{|c|}{$28 \mathrm{~d} / \mathrm{MPa}$} \\
\hline & & & $\begin{array}{l}\text { Initial } \\
\text { setting }\end{array}$ & $\begin{array}{l}\text { Final } \\
\text { setting }\end{array}$ & $\begin{array}{l}\text { Flexural } \\
\text { strength }\end{array}$ & $\begin{array}{c}\text { Compressive } \\
\text { strength }\end{array}$ & $\begin{array}{l}\text { Flexural } \\
\text { strength }\end{array}$ & $\begin{array}{c}\text { Compressive } \\
\text { strength }\end{array}$ \\
\hline 26.8 & 0.5 & Qualified & 199 & 269 & 6.4 & 26.7 & 8.3 & 48.6 \\
\hline
\end{tabular}


residue) $13 \%$, loss on ignition $3.4 \%$, water demand ratio $100 \%$. The physical properties cement and II fly ash are determined as per IS 1727-1967[13]

Aggregate: Fine Aggregate - Chengdu Machinemade Sand, its fineness modulus 2.6, MB value 1.3. Coarse aggregate, continuous grading, $5-25 \mathrm{~mm}$, clay content $1.4 \%$ 。

Others: poly-carboxylate water reducer, modifier, reclaimed brick micro-powder, recycled concrete micropowder.

\subsection{Testing methods}

The specific surface area of the recycled micro-powders were measured by the Brad's method according to GB 8074 - 2008 [14]. The adaptability of the recycled micropowders were measured by the ratio of the fluidity between reference paste and recycled paste which 30\% cement was replaced by the recycled micro-powders according to GB/T $8077-2012$ [15]. The strength activity index of the recycled micro-powders were measured by the ratio of the compressive strength between reference mortar and recycled mortar which $30 \%$ cement was replaced by the recycled micro-powders according to
GB/T 1596 - 2005 [16]. The fluidity of mortar was measured by flow table test according to GB/T 2419 2005 [17]. The compressive and flexural strength were determined according to method of GB/T 17671 - 1999 [18] and conducted on the prism mortar and the concrete specimens with dimension of $40 \mathrm{~mm} \times 40 \mathrm{~mm} \times 160 \mathrm{~mm}$ and $100 \mathrm{~mm} \times 100 \mathrm{~mm} \times 100 \mathrm{~mm}$. And evaluation of the workability of fresh concrete with reference to the test method specified in GB/T 50080-2016 [19]; and evaluation of concrete strength according to GB/T 500812002 [20]; The particle size distribution of the powder particles was determined by laser particle size analysis, and the phase and mineral components were analyzed by XRD. The microscopic characteristics were characterized by SEM.

\section{Results and discussion}

\subsection{Comparison of characteristics of regenerated powder}

Table 2 shows the main chemical components of the II fly ash, recycled brick micro-powders and recycled concrete micro-powder

Table 2.Main chemical components of fly ash and reclaimed powder

\begin{tabular}{cccccccc}
\hline \multirow{2}{*}{ category } & \multicolumn{6}{c}{ The main chemical composition } & \multirow{2}{*}{ L.O.I (\%) } \\
\cline { 2 - 6 } & $\mathrm{SiO}_{2}$ & $\mathrm{CaO}$ & $\mathrm{Fe}_{2} \mathrm{O}_{3}$ & $\mathrm{Al}_{2} \mathrm{O}_{3}$ & $\mathrm{MgO}$ & \\
\hline \multirow{2}{*}{ II Fly ash } & 52.10 & 3.52 & 5.31 & 30.25 & 1.69 & 4.05 \\
Recycled brick powder & 69.23 & 6.45 & 3.01 & 12.11 & 2.01 & 4.98 \\
Recycled concrete powder & 38.12 & 26.88 & 3.05 & 9.12 & 2.96 & 18.6 \\
\hline
\end{tabular}

From Table 2, it can be seen that the main chemical components of the reclaimed brick fines and fly ash are similar, and the quality of $\mathrm{SiO} 2$ and $\mathrm{A} 12 \mathrm{O} 3$ is relatively high. The main raw material of the brick is clay, so the percentage of $\mathrm{SiO} 2$ in the recycled brick powder is relatively high, which is $69.23 \%$. The mass percentage of $\mathrm{Al} 2 \mathrm{O} 3$ is lower than fly ash. Recycled concrete micropowder is mainly based on $\mathrm{SiO} 2$ and $\mathrm{CaO}$, and because of the cement firing raw materials and part of the sandstone parent rock component, the $\mathrm{CaO}$ content is much larger than that of recycled brick micro-powder. The ignition loss of fine powder of recycled concrete is mainly due to the loss of cement chemically combined water and the high temperature calcination of other concrete raw materials.

From the data in Fig. 1 and Table 3, it can be seen that the average fineness of the ground fine powder is consistent, the particle size of the recycled brick powder is mainly concentrated at $3.87 \mu \mathrm{m}$, and the distribution of the fine powder particles of the recycled concrete is relatively scattered; II. Fine particle distribution of fly ash and recycled concrete powder Similar, but more coarse particles; three kinds of micro-powder are finely ground

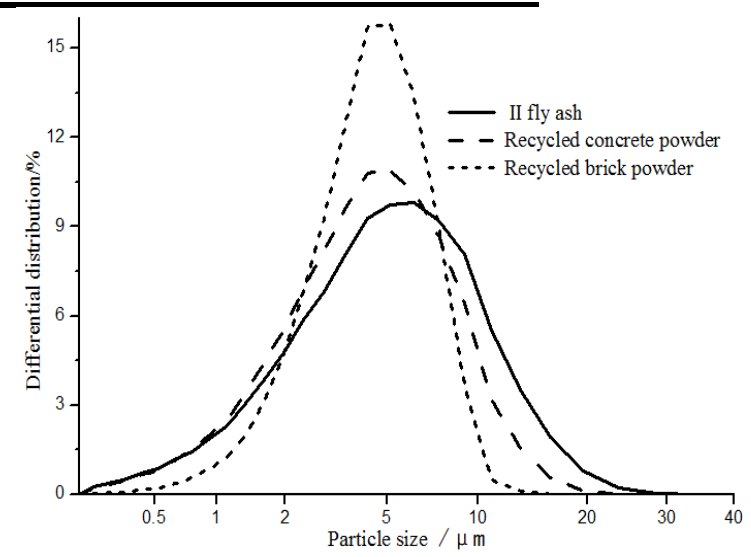

Figure 1. Particle size distribution of fly ash and powder.

Table 3. the D50 data of the Powder

\begin{tabular}{cccc}
\hline category & $\begin{array}{c}\text { II } \\
\text { Flay } \\
\text { ash }\end{array}$ & $\begin{array}{c}\text { Recycled brick } \\
\text { micro-powder }\end{array}$ & $\begin{array}{c}\text { Recycled } \\
\text { concrete micro- } \\
\text { powder }\end{array}$ \\
\hline $\mathrm{D} 50 / \mu \mathrm{m}$ & 4.14 & 3.87 & 3.66 \\
\hline
\end{tabular}




\subsection{Research on the properties of regenerated fine powder}

As a mineral admixture, the regenerated fine powder must consider its effect on the workability and strength of the concrete. Fig. 2 and Fig. 3 respectively study the activity index and fluidity ratio of recycled fine brick powder and recycled concrete fine powder of different fineness. From Fig. 2, we can see that the activity index of recycled brick powder $7 \mathrm{~d}$ and $28 \mathrm{~d}$ increases with the increase of the specific surface area of the fine powder; and the flow ratio increases first with the increase of the specific surface area, when the specific surface area reaches $4600 \mathrm{~cm}^{2} / \mathrm{g}$.

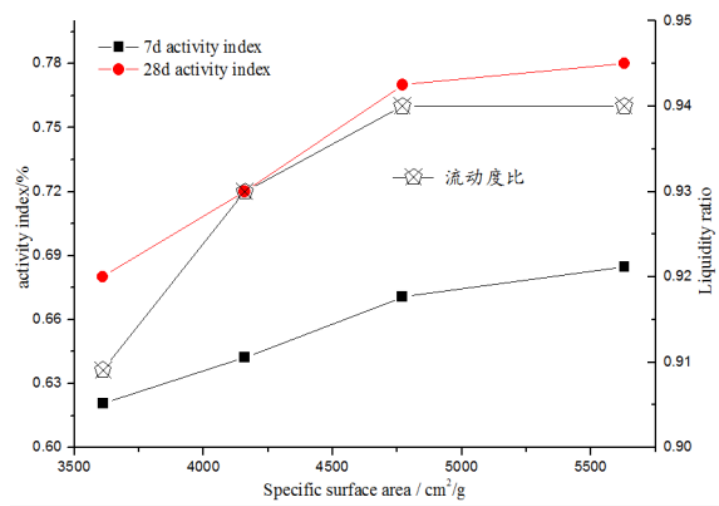

Figure 2. Activity index and fluidity ratio of recycled bricks micro-powder

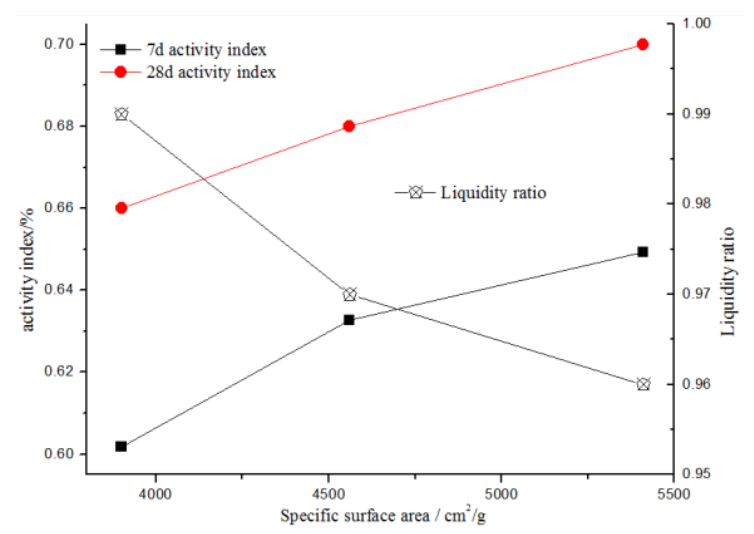

Figure 3. Activity index and fluidity ratio of recycled concrete micro-powder

It tends to maintain a balance of about $94 \%$, which is equivalent to the performance of Class II fly ash. As can be seen from Fig. 3, the activity index of the recycled concrete micro-powder increases with the increase of the specific surface area, while the flow ratio decreases with the increase of the specific surface area; the specific surface area is $5500 \mathrm{~cm} 2 / \mathrm{g}$, only with the class II fly ash. The performance is comparable; from Fig. 2 and Fig. 3, it can be seen that the activity index of recycled brick powder is higher than that of recycled concrete, and the degree of fluidity is greater than that of recycled concrete.

Table 4 Reproduce Micro-powder Mixture Ratio and Workability Description

\begin{tabular}{|c|c|c|c|c|c|c|c|c|c|c|}
\hline \multicolumn{2}{|c|}{ Number cement } & \multirow{2}{*}{$\begin{array}{c}\begin{array}{l}\text { II fly } \\
\text { ash }\end{array} \\
60\end{array}$} & \multirow{2}{*}{$\begin{array}{c}\begin{array}{c}\text { Recycled brick } \\
\text { micro-powder }\end{array} \\
0\end{array}$} & \multirow{2}{*}{$\begin{array}{c}\text { Recycled concrete } \\
\text { micro-powder }\end{array}$} & \multirow{2}{*}{$\begin{array}{c}\begin{array}{c}\text { Coarse } \\
\text { aggregate }\end{array} \\
960\end{array}$} & \multirow{2}{*}{$\begin{array}{c}\begin{array}{c}\text { Fine } \\
\text { aggregate }\end{array} \\
930\end{array}$} & \multirow{2}{*}{$\begin{array}{c}\begin{array}{c}\text { Water } \\
\text { reducer }\end{array} \\
2.1 \%\end{array}$} & \multicolumn{2}{|c|}{ Modifiers water } & \multirow{2}{*}{$\begin{array}{c}\mathrm{K} / \mathrm{T} \\
\text { The initial state: } 235 / \\
580 ; 1.5 \mathrm{~h}: 160 / 390\end{array}$} \\
\hline $\mathrm{JZ}-1$ & 320 & & & & & & & 0 & 175 & \\
\hline ZS - 1 & 320 & 0 & 60 & 0 & 960 & 930 & $2.2 \%$ & 0 & 175 & $\begin{array}{c}\text { The initial state: } 235 / \\
600 ; 1.5 \mathrm{~h}: \text { No } \\
\text { mobility }\end{array}$ \\
\hline $\mathrm{ZS}-2$ & 320 & 0 & 0 & 60 & 960 & 930 & $2.3 \%$ & 0 & 175 & $\begin{array}{c}\text { The initial state: } 240 / \\
625 ; 1.5 \mathrm{~h}: \text { No } \\
\text { mobility }\end{array}$ \\
\hline $\mathrm{JZ}-2$ & 320 & 60 & 0 & 0 & 960 & 930 & $2.0 \%$ & $0.5 \%$ & 175 & $\begin{array}{l}\text { The initial state: } 230 / \\
610 ; 1.5 \mathrm{~h}: 200 / 500\end{array}$ \\
\hline ZS-3 & 320 & 0 & 60 & 0 & 960 & 930 & $2.1 \%$ & $0.5 \%$ & 175 & $\begin{array}{l}\text { The initial state: } 240 / \\
620 ; 1.5 \mathrm{~h}: 220 / 580\end{array}$ \\
\hline $\mathrm{ZS}-4$ & 320 & 0 & 0 & 60 & 960 & 930 & $2.2 \%$ & $0.5 \%$ & 175 & $\begin{array}{l}\text { The initial state: } 235 / \\
625 ; 1.5 \mathrm{~h}: 215 / 600\end{array}$ \\
\hline
\end{tabular}

Select reclaimed brick powder and recycled concrete micro-powder with similar flow rate ratio and activity index of class II fly ash, and study its effect on the workability and mechanical properties of concrete; Table 4 shows the test of recycled fine powder and II fly ash as admixtures. Matching ratio and working status 。

From Table 4, it can be seen that the regenerated fine powder has a certain influence on the admixture dosage, but it does not fluctuate significantly within $0.2 \%$; however, it has a negative effect on the maintenance of workability of the concrete, and the experiment of adding regenerated fine powder after 1.5 hours. The group has no mobility; based on the characteristics of the regenerated fine powder, a modifier was developed, which has a significant effect on the retention time of the concrete mixture containing regenerated fine powder and II fly ash, and can guarantee concrete mixing after 1.5 hours. The slump loss of material is within $30 \mathrm{~mm}$, and the variation of the degree of expansion of the doped regenerated fine powder is small, and the fluidity is good.

The influence of regenerated fine powder on the mechanical properties of concrete is shown in Fig. 4. It can be seen from Table 4 and Fig. 4 that the modifier has obvious improvement and improvement effect on the 
concrete's water repellency and its late strength, but it has a certain inhibitory effect on the $7 \mathrm{~d}$ strength. Mainly because of the presence of retarder components in the modifier, the early strength of the concrete develops slowly. In summary, using recycled micro-powder instead of II fly ash can produce concrete that satisfies construction requirements and strength grades under the conditions of incorporating modifiers.

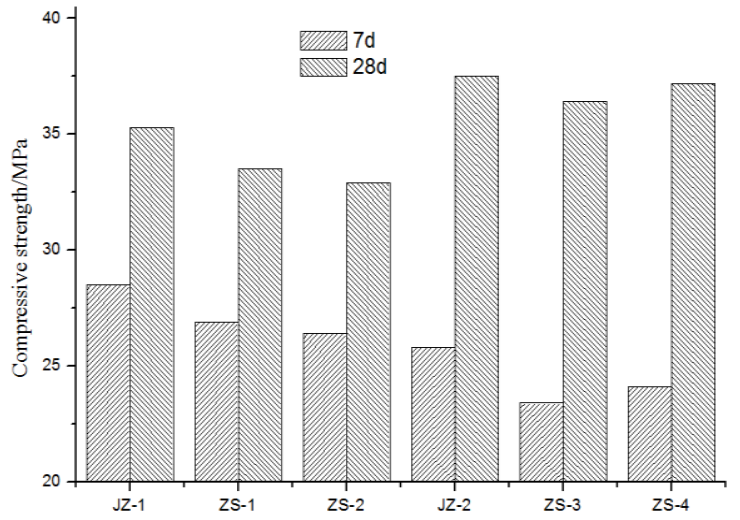

Figure 4. Strength values of $7 \mathrm{~d}$ and $28 \mathrm{~d}$ in each experimental group

\subsection{Microscopic mechanism analysis}

The modifier is mainly composed of organic retarder and activator and surfactant. Its effect on the workability of concrete is mainly detrimental to the retarder and surfactant, and has three major effects on the later strength. Components have a certain degree of synergy.

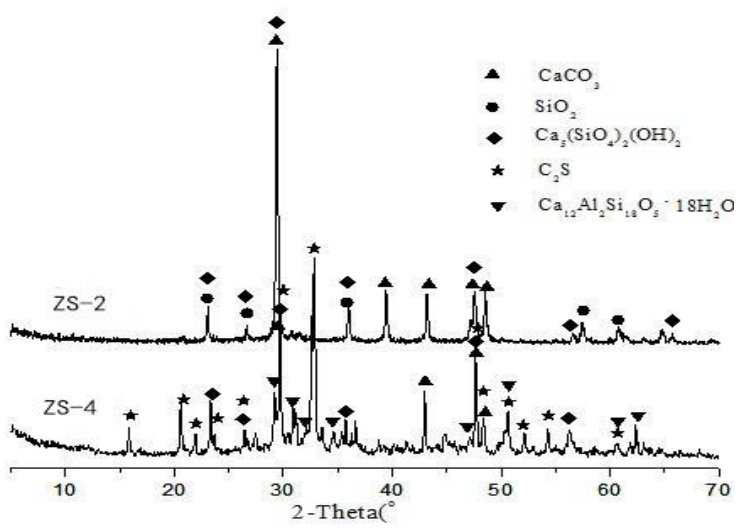

Figure 5.The XRD pattern of ZS-2 and ZS-4 groups in the $28 \mathrm{~d}$ hydration age

Figure 5 shows The XRD pattern of ZS-2 and ZS-4 groups in the $28 \mathrm{~d}$ hydration age [21]. It can be seen from the figure that the amount of hydration products in the ZS-2 group without modifiers is small, mainly high Alkaline hydrated calcium silicate $(\mathrm{Ca} 5(\mathrm{SiO} 4) 2(\mathrm{OH}) 2)$ [11], which is a small amount of components in the cement hydration reaction and in the recycled concrete micro-powder; compared to the ZS-2 group, it incorporates a modifier In addition to the highly alkaline hydrated calcium silicate $\mathrm{Ca} 5(\mathrm{SiO} 4) 2(\mathrm{OH}) 2$, the hydration products of the ZS-4 group also produced a large amount of hydrated calcium aluminosilicate
(Ca15Al2Si18O5•18H2O) due to the raw water in the recycled concrete micro-powder. The presence of [AlO4]4-in the product system [12], but no hydration of calcium aluminosilicate in the ZS-2 group, indicating that the added modifier has a certain stimulating effect in the presence of the modifier Hydrated calcium aluminosilicate, which can form a network structure, are conducive to the improvement of strength; and they also verify the reasons for their enhanced strength at later stages of concrete.
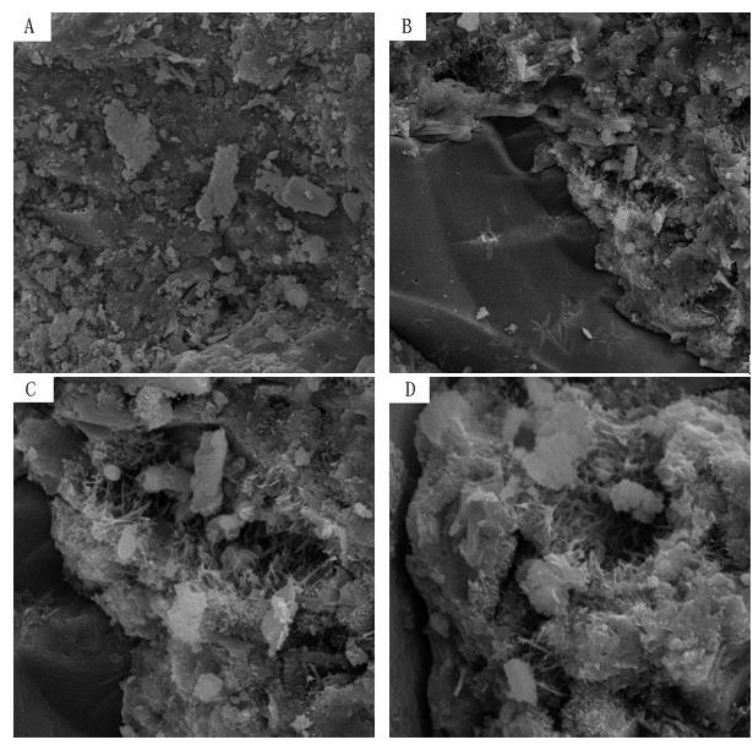

Figure 6. SEM Images of ZS-4(A) and ZS-2(B, C, D) Groups

Fig. 6 shows SEM images of hardened concrete in which fly ash is replaced by fly ash instead of fly ash, and the ZS-4 and ZS-2 scales are magnified 2000 times; Fig. 6C and $6 \mathrm{D}$ are ZS-2 enlarges the pattern of 5000 . As can be seen from Fig. $6 \mathrm{~A}$ and $6 \mathrm{~B}$, the entire interface of $\mathrm{ZS}-4$ is denser, while there is an interface defect in Fig. $6 \mathrm{~B}$, and there are a small amount of AFt in the hydration gel in Fig. $6 \mathrm{C}$ and $6 \mathrm{D}$, and there is no significant $\mathrm{AFt}$ diffraction peak in Fig. 5. Appears; and there is a visible crack in the interface junction in Fig. 6D. It is proved that the ZS-4 group has a more compact structure through the excitation of the modifier under the condition that the early strength develops slowly; and the formation of $\mathrm{AFt}$ in the ZS-2 hydration process requires a certain space, and its density is low. On the ZS-4. The modifier can inhibit the formation of AFt in the early stage and stimulate the reaction of the recycled concrete micropowder to form a cement hardened body with high tightness and compactness, and improve the late strength of the concrete.

\section{Conclusions}

1. The fine powder of recycled brick powder and the powder of recycled concrete can be used as admixture instead of II fly ash under certain fineness conditions. The performance of fine powder is equivalent to that of II fly ash.; 
2. The modifier can improve the slump loss of the concrete over time, and the slump loss after 30 hours is $30 \sim 40 \mathrm{~mm}$, which meets the working requirements of commercial concrete.;

3. The modifier can increase the strength of the concrete to some extent. The amount of hydration calcium aluminosilicate in the hydration product increases; and the interfacial junction can be improved. The composition is mainly retardation and excitation components.;

4. After the reclaimed micro-powder is incorporated into the modifier, it can meet the requirements of commercial concrete for workability and mechanical properties.

\section{References}

1. Mao Xinqi, Qu Wenjun, Zhu Peng. Current research status of construction waste reclaimed micropowders[J]. Concrete \& Cement Products, 2015, 8:89-93. (in Chinese)

2. Lee, S., Park, W.J., Lee, H.S., 2013. Life cycle CO2 assessment method for concrete using $\mathrm{CO} 2$ balance and suggestion to decrease LC CO 2 of concrete in South-Korean apartment. Energy. Build. 58, 93e102.

3. Fang Qianqian, $\mathrm{Yu}$ Linfeng, Wang Qiong. Experimental research on the use of recycled fine powder of construction waste for concrete $[\mathrm{J}]$. Fly ash, 2015, 06:27-29. (in Chinese)

4. Chen Xue, Li Qiuyi, Yang Xiangning, Lian Xuechao. Performance and Application of Regenerated Micro powders [J]. Journal of Qingdao Technological University, 2013, 03:17-21. (in Chinese)

5. WANG Haijin, KUO Hai, ZHAO Guiyun. Experimental Study on Basic Properties and Sand Strength of Reclaimed Micropowders [J]. Concrete, 2015(8): 74-77. (in Chinese)

6. MA Yu. Experimental study on properties of recycled micro-concrete mixed with construction waste [J]. Concrete \& Cement Products, 2016,10:8890. (in Chinese)

7. Qi Bin, Li Jianyong, Li Rongjiang, Zhang Zhaowei, Ma Xueying. Synthesis of functional polycarboxylate superplasticizer and its application in recycled fine powder concrete $[\mathrm{J}]$. Jiangxi Building Materials, 2015, 12:165-170. (in Chinese)

8. NPCSC, 2017. Implementation Report on the Republic of Solid Waste Pollution Prevention Law. Beijing, China.
9. Aliabdo, A.A., Elmoaty, A.E.M.A., Auda, E.M., 2014. Re-use of waste marble dust in the production of cement and concrete. Constr. Build. Mater 50, $28 \mathrm{e} 41$.

10. Li XP. Recycling and reuse of waste concrete in China Part I. Material behavior of recycled aggregate concrete. Resour Conserv Recyc 2008; 53 (1):36-44.

11. A.A. Aliabdo, Abd-Elmoaty M. Abd-Elmoaty, H.H. Hassan, Utilization of crushed clay brick in concrete industry, Alex. Eng. J. 53 (2014) 151-168.

12. D. Tavakoli, A. Heidari, S.H. Pilehrood, Properties of concrete made with waste clay brick as sand incorporating nano $\mathrm{SiO} 2$, Indian J. Sci. Technol. 7 (12) (2014) 1899-1905.

13. IS : 1727 - 1967, Indian Standard Methods of Test for Pozzolanic Materials (R), Bureau of Indian Standards, New Delhi, India, 2004.

14. GB8074-2008, Chinese Standards, Determination of cement specific surface area (Brad's method), Chinese Standards Association, China, 2008.

15. GB/T 8077 - 2012, Chinese Standards, Concrete admixture homogeneity test method, Chinese Standards Association, China, 2012.

16. GB/T 1596-2005, Chinese Standards, Fly Ash used for Cement and Concrete, Chinese Standards Association, China, 2005.

17. GB/T 2419-2005, Chinese Standards, Test Method for Fluidity of Cement Mortar, Chinese Standards Association, China, 2005.

18. GB/T 17671, Chinese Standards, Cement mortar strength test method, Chinese Standards Association, China, 1999.

19. GB/T 50080-2016, Chinese Standards, Standard for Testing Methods for Performance of Normal Concrete Mixtures, Chinese Standards Association, China, 2016.

20. GB/T 50081-2002, Chinese Standards, Standard for Testing Methods for Mechanical Properties of Normal Concrete, Chinese Standards Association, China, 2002.

21. Yang Nanru, Yue Wenhai. Inorganic non-metallic material map manual [M]. Wuhan: Wuhan University of Technology Press, 2000: 65 (in Chinese) 